\title{
How are balance and mobility problems after stroke treated in England? An observational study of the content, dose and context of physiotherapy
}

DOI:

10.1177/0269215518777789

\section{Document Version}

Accepted author manuscript

Link to publication record in Manchester Research Explorer

Citation for published version (APA):

Tyson, S. F., Woodward-Nutt, K., \& Plant, S. (2018). How are balance and mobility problems after stroke treated in England? An observational study of the content, dose and context of physiotherapy. Clinical Rehabilitation. https://doi.org/10.1177/0269215518777789

\section{Published in:}

Clinical Rehabilitation

\section{Citing this paper}

Please note that where the full-text provided on Manchester Research Explorer is the Author Accepted Manuscript or Proof version this may differ from the final Published version. If citing, it is advised that you check and use the publisher's definitive version.

\section{General rights}

Copyright and moral rights for the publications made accessible in the Research Explorer are retained by the authors and/or other copyright owners and it is a condition of accessing publications that users recognise and abide by the legal requirements associated with these rights.

\section{Takedown policy}

If you believe that this document breaches copyright please refer to the University of Manchester's Takedown Procedures [http://man.ac.uk/04Y6Bo] or contact uml.scholarlycommunications@manchester.ac.uk providing relevant details, so we can investigate your claim.

\section{OPEN ACCESS}




\section{Clinical Rehabilitation}

\section{How are balance and mobility problems after stroke treated in the UK? An observational study of the content, dose and context of physiotherapy.}

\begin{tabular}{|r|l|}
\hline Journal: & Clinical Rehabilitation \\
\hline Manuscript ID & CRE-2017-6829.R1 \\
\hline Danuscript Type: & Original Article \\
\hline Complete List of Authors: & $\begin{array}{l}\text { Tyson, Sarah; University of Manchester , Stroke \& Vascualr Research } \\
\text { Centre } \\
\text { Plant, Sarah; University of Manchester, School of Nursing, midwifery and } \\
\text { social work } \\
\text { Woodward-Nutt, Kate; University of Manchester, School of Nursing, } \\
\text { Midwifery and Social Work }\end{array}$ \\
\hline Keywords: & Balance, Physical Therapy, Physiotherapy, Mobility, dose \\
\hline & \\
\hline
\end{tabular}

SCHOLARONE ${ }^{\text {tw }}$

Manuscripts 


\begin{abstract}
Objective: To describe the dose, intensity and context of physiotherapy for balance and mobility problems after stroke.
\end{abstract}

Design: Process mapping to describe the context and non-participant observation of therapy sessions to describe the dose and content of therapy

Setting: Four in-patient stroke units in North-West England

Participants: Therapy staff and previously mobile stroke survivors who were treating, or receiving treatment for balance and mobility problems in the participating units.

Results: Two units were stand-alone rehabilitation units; two offered a service at the weekends. One had no access to community based rehabilitation. All had dedicated treatment facilities but often did not use them because of difficulty transporting patients. 22 patients participated and 100 treatment sessions were observed. Practicing walking, sit-to-stand and transfers were the most frequent objectives and interventions usually with the therapist(s) physically facilitating the patient's movements. The dose of practise was low; mean repetitions of sit-to-stand per session was 5 (sd 6.4); mean time spent upright per session was $11.24(\mathrm{sd}=7)$ minutes, and mean number of steps per session was 202 (sd 118). The mean number of staff per patient was $2.1(\mathrm{sd}=0.6$, mode $=2)$, usually involving two qualified therapists. Falls prevention or management, wheelchair skills and bed mobility were not practised.

Conclusion: Stroke physiotherapy for balance and mobility problems features low dose therapist-led practice, mainly of walking and sit-to-stand. Staff: patient ratios were high. Therapists need to organise treatment sessions to maximise the intensity of functional task practice. 
Physiotherapy for balance and mobility after stroke

\section{Introduction}

Limited balance and mobility are amongst the most common and disabling effects of stroke and frequently a high priority of stroke rehabilitation for both patients and health care professionals $[1,2]$. There is strong evidence that the most effective interventions to promote balance and mobility after stroke are exercise and the intensive practice of functional tasks $[3,4]$. The amount of therapy and intensity with which functional tasks are practiced are important factors with higher doses associated with better outcomes [5,6]. National Clinical Guidelines for Stroke typically recommend that stroke patients should receive 45- 60 minutes of physiotherapy per day. However, these targets are often unmet [7,8]. This is a particular issue in the UK, where patients typically receive only 35 minutes of physiotherapy on 3-4 days per week [9]. Surveys of stroke physiotherapy for balance and mobility problems during in-patient stroke care in the UK (albeit a decade ago) showed therapy focussed on low-dose, low-intensity, therapist-led mobilisations and facilitation techniques in which the patient was often passive and undertook little actual practice of functional activities such as walking, standing up and sitting down or keeping one's balance under different conditions [10,11].

The context in which therapy is delivered is a key factor influencing the dose of therapy [5,12-14 -12]. Environmental issues (lack of space, equipment and facilities) and lack of resources (particularly lack of time and staff) are consistently reported as barriers to successful implementation of evidence based stroke physiotherapy [15-17].

Our aim was to describe the dose, intensity and context of therapy for balance and mobility problems after stroke. 
Physiotherapy for balance and mobility after stroke

\section{Method}

A mixed methods approach was taken using two data collection methods; process mapping to describe the context in which therapy was delivered, and non-participant observations of physiotherapy treatment sessions for balance and mobility problems to describe the dose and intensity of the therapy. Ethical approval was obtained from the London - Hampstead Research Ethics Committee (reference 15/LO/2023/193142).

As our aim was to obtain a generalizable sample, our inclusion criteria were very broad. We recruited physiotherapists in the participating stroke rehabilitation services who delivered rehabilitation for balance and mobility problems. They took part in the process mapping and the observational study. Patient participants were receiving treatment for balance and/or mobility problems in the participating stroke rehabilitation units and were able to sit unsupported for 30 seconds or more. They took part in the observational study only. Patients who were unable to walk before their stroke or were unable to give consent were excluded.

Process mapping is a systematic approach to document the steps and resources required to complete a task, in this case rehabilitation for balance and mobility [18]. At each stroke unit, participating staff were asked about how balance and mobility rehabilitation was delivered in their service; the resources available; the processes involved, and the interventions used. Two of the authors (KWN and SP) facilitated the meetings and also acted as scribes. Both are experienced specialist stroke/ neurological therapists, an occupational therapist and physiotherapist respectively. They recorded the answers, comments and suggestions on flip charts which were visible to all participants. Any details, ambiguities or uncertainties were clarified during the discussion. At the end of the session, the facilitators made field notes. 
Physiotherapy for balance and mobility after stroke

These and the flip charts were transcribed and returned to the participants for feedback regarding clarity and accuracy.

KWN and SP also undertook the data collection in the observation study to record the dose and intensity of therapy. They observed the therapy sessions for balance and mobility problems (as indicated by the treating therapists) involving the patient participants from Monday-Friday during normal working hours over a four week period at each participating unit. During each therapy session, they recorded the:

- $\quad$ staff involved

- location(s) of treatment

- duration of treatment (from start to finish, including any rest periods, interruptions etc)

- interventions used (using a proforma (Appendix 1) adapted from a previous study [19])

- amount of time spent sitting and standing

- number of steps taken

- number of times patients stood up and sat down.

Durations were recorded using a stopwatch and the number of repetitions was recorded using a 'click counter'. At the end of each treatment session, the lead treating therapist identified the main objective of the treatment session and factors which had limited the amount or type of therapy provided.

For each patient participant, gender, age, side of hemiplegia, days since stroke and level of mobility disability (Rivermead Mobility Index [20]) were recorded at the $1^{\text {st }}$ observed treatment session. 
Physiotherapy for balance and mobility after stroke

Descriptive statistics were used for the analysis. Themed content analysis was used to categorise the treatment objectives and factors limiting treatment.

\title{
Results
}

47 qualified stroke physiotherapists participated (8-17 per unit). Eleven were men. When asked about the treatment approach they used, none felt they followed a specific treatment approach and reported that their choice of interventions was based in their "clinical reasoning" and individual patients' needs.

Four specialist stroke units participated, two were a 'stand-alone' rehabilitation unit (16-31 rehabilitation beds) with a separate acute stroke unit, and two combined acute stroke care and rehabilitation (22 beds). One combined (acute and rehabilitation) stroke unit offered physiotherapy from 8.00 am until $7.00 \mathrm{pm}$, seven days per week. The other had physiotherapy cover over a traditional eight hour day (8.30am to $4.30 \mathrm{pm})$ on weekdays and offered assessment at the weekend but not treatment. The two rehabilitation units did not provide physiotherapy over the weekends.

\begin{abstract}
All units had a dedicated treatment area: a gym with wide treatment plinths; two also had parallel bars and one had access to a treadmill (which was situated in another part of the hospital). They all had access to a therapy kitchen or Activities of Daily Living suite. Three had access to a staircase for treatment purposes which was separate from general traffic but in one unit patients had to use a hospital staircase. Three used the corridor on the ward for walking practice but one had to use a hospital corridor. None of the units had portering staff to transport patients to and from therapy; all patient transport was undertaken by the therapists. Most treatment sessions occurred on the ward (at the bedside; in the ward or on the
\end{abstract}


Physiotherapy for balance and mobility after stroke

corridor, $n=32,32 \%)$ with only $25(25 \%)$ of treatment sessions used the treatment area. The remaining treatment sessions used a combination of treatment area and ward based locations.

Twenty-two stroke patients participated. Twelve were female, thirteen had a left hemiplegia, seven had a right hemiplegia; one was bilateral and one had cerebellar symptoms. Mean age was 67.9 (sd 12.3) years, mean time since stroke was 36.7 ( $\mathrm{sd} 40.1)$ days. The mean Rivermead Mobility Index score was 4.1 ( $\mathrm{sd}=1$, minimum- maximum = 3-7), of whom six had sitting balance only (RMI=3); eleven had sitting balance and could stand up but did not have standing balance $(\mathrm{RMI}=4)$; four had standing balance and/or could transfer $(\mathrm{RMI}=5$ or 6) and one could walk short distances with an aid but without assistance of another person (RMI=7).

One hundred treatment sessions were observed, on average 4.5 (sd 3) sessions per participant were observed. The mean duration of treatment session was 28.7 (sd 14.14, range 4-57) minutes. When treated, patients received only one session per day. The therapists perceived they provided more frequent, short sessions when patients were unable to tolerate a 'full' treatment session (typically considered to be 30-60 minutes) but this was not observed during the data collection period. The physiotherapists reported that half of all sessions $(n=51)$ were limited by external factors. The most frequent cause was the patients' fatigue ( $n=25,49 \%$ of limited sessions) but pain ( $\mathrm{n}=8,16 \%$ of limited sessions) and lack of concentration $(n=5,10 \%$ of limited sessions) were also reported by therapists to limit patients' ability to engage with their treatment.

The most frequently reported treatment objective for the observed treatment sessions were:

- Walking ( $\mathrm{n}=55,46 \%$ of treatment sessions)

- $\quad$ Sit-to-stand ( $\mathrm{n}=14,12 \%$ of treatment sessions) 
Physiotherapy for balance and mobility after stroke

- Walking plus other mobility activities. The other activities were sit-to-stand, transfers, standing balance and/or stairs $(n=17,14 \%)$.

Although practicing functional activities were the most frequently reported objective, improving impairments such 'regaining mid-line orientation' (ie a symmetrical posture) and/ or symmetrical weight-bearing also featured $(\mathrm{n}=13,11 \%$ of treatment sessions) (Figure 1$)$.

\section{Figure 1 about here}

Three hundred and fifty-seven interventions were recorded (Figure 2). Practicing activities (walking, sit-to-stand and transfers) were the most frequent interventions; most commonly using 'hands on techniques', i.e. with the therapist physically guiding or facilitating the patients' movements. Approximately two-thirds of the time, this involved the patient practicing the whole task, rather than 'part-task practice' when the task was broken down in to constituent components (eg the specific stages of stance and swing phase of walking) which were practiced one-third of the time.

\section{Figure 2 about here}

The actual dose of practise of these activities was low (Table 1). The mean number of repetitions of sit-to-stand (number of times participants stood up and sat down) per treatment sessions was 5 (sd 6.4, range 1-24). The time spent upright (standing, sit-to-stand and walking combined) and the number of steps per treatment session were also low. Notably, the number of steps were heavily skewed by four treatment sessions in which a treadmill was used (Table 1).

\section{Table 1 about here}

Sitting or standing balance was practiced 68 times (in 19\% of treatment sessions) but this most commonly involved static $(n=45)$, rather than dynamic $(n=23)$ activities. Bed mobility 
Physiotherapy for balance and mobility after stroke

was practiced in only $3 \%$, and stairs in only $8 \%$ of sessions. Interventions related to falls prevention or management, wheelchair skills and stretching exercises were never used. Bed mobility was practised in only three treatment sessions.

A striking feature of the treatment provided was the number of staff involved and the predominance of qualified staff. The mean number of staff per patient was $2.1(\mathrm{sd}=0.6$, mode $=2$ ). Two members of staff were involved in the following combinations:

- two qualified therapists ( $\mathrm{n}=34$ sessions)

two physiotherapists (17 sessions)

$\circ$ one physiotherapist and one occupational therapist.(17 sessions)

- one physiotherapist and one unqualified member of staff

- Physiotherapist and therapy assistant (22 sessions)

○ Physiotherapist and student physiotherapist (5 sessions)

Approximately a quarter of treatment sessions involved three staff (23\%) and 5 involved 4 staff. Only 11 treatment sessions (11\%) were undertaken by a single therapist. One treatment session involved a physiotherapy assistant working alone, plus one session involved two assistants.

\section{Discussion}

The results of this study indicate that, in the participating units, treatment for balance and mobility problems after stroke focusses on low dose, therapist-facilitated practice of functional tasks, primarily walking and sit-to-stand. This demonstrates a change in practice over the last decade. In previous work published in 2006-2009 (using a self-reported treatment log, rather than non-participant observation), we reported that physiotherapy for 


\section{Physiotherapy for balance and mobility after stroke}

balance and mobility problems focussed on normalising muscle tone and promoting normal movement patterns using mobilisation and facilitation techniques and practicing the components of tasks (rather than the whole task) [10,11]. In the current study, although facilitation (referred to as 'hands on techniques'), 'part task practice' and 'symmetrical posture and movement' still featured, there had been a shift towards practicing functional tasks. Mobilisation techniques were seldom used. Given that the strongest evidence base is for interventions which enable exercise and practicing functional tasks [3,4], this could be considered a welcome move towards evidence-based practice.

Nevertheless, the intensity with which patients practiced functional tasks was low, typically five repetitions of sit-to-stand or $\sim 180$ steps in a session lasting 28 minutes. While these figures are only a little below reports of the dose of practice in other studies [15,21,22], they fall well below the duration of therapy in other countries [6] and national guidance, which recommends that patients should receive at least 45 minutes of physiotherapy per day $[7,8]$. In the current study, only $10(10 \%)$ sessions reached this standard. There is therefore an imperative to find ways to deliver more therapy and greater intensity of practice during therapy. The feasibility of increased treatment intensity was illustrated by the small group of patients $(n=4)$ who were treated using a treadmill. The physiotherapists in one site started to use the treadmill towards the end of our observation period after they attended an in-service training session on evidence-based gait rehabilitation. Patients who used the treadmill took three times more steps than those who did not (636 steps vs 182). Further research to examine the barriers to implementing effective interventions to increase the intensity of practice, such as treadmill training [24], electro-mechanical gait training [25], and circuit training [26] - and how to overcome them is warranted.

Lack of staff or time are frequently cited by clinicians as a reason for the low intensity of therapy after stroke [15-17]. Although therapy staffing levels often fall below recommended 
Physiotherapy for balance and mobility after stroke

levels [9] the way that therapists' time and workload is organised has a greater effect on therapists' availability to provide treatment $[14,19]$. Physiotherapists rarely treated patients alone. They often worked in pairs of qualified staff, or even higher therapist: patient ratios. Unqualified staff (therapy assistants) were seldom involved. The rationale for these high staffing ratios is unclear. It may be a reflection of the relatively high level of disability in our participating patients, but unpublished data from our previous surveys $[13,14]$ suggest a change in practice. Then, a 1:1 therapist: patient ratio was the norm, and if more than one person was required to treat a patient, a therapy assistant would usually be involved. Further research is needed to explore the reasons behind these high staffing ratios, and the policy, behavioural or cultural changes needed to promote more efficient use of staff resources.

Staff resources were also observed to influence the location of treatment, although all the participating stroke units had access to specific treatment areas and facilities, these often went unused (only $25 \%$ of treatment sessions) and patients were most frequently treated on the ward area. This may be due to a lack of portering staff to transport patients, which meant it was more efficient for therapists to treat patients in the ward areas rather than spend time transporting them to and from the treatment areas. Again, further research to investigate the most efficient way of resourcing stroke rehabilitation is needed.

When considering these results, several limitations need to be born in mind. Firstly, we have observed a large number of treatment sessions, but in only four hospitals in a single region of England. It cannot be assumed that the results are generalizable to all stroke units, particularly to those outside the UK. However data from the Sentinel Stroke National Audit Programme [9], indicate that the participating units are not unusual in terms of the number of beds, type of unit, patient characteristics and amount of therapy provided. We therefore believe that our results are broadly representative to stroke rehabilitation units in the England, Wales and Northern Ireland. Stroke physiotherapy in other countries also often fails to reach 
Physiotherapy for balance and mobility after stroke

recommended doses [6] and the intensity of practice is also reported to be low $[15,21,22]$, but to a lesser extent than in the present study. Thus, although our findings are in line with others countries, they cannot be considered directly representative.

We only observed 'direct contact' treatment sessions between therapists and patients, we did not observe work that may have gone on to promote activity outside treatment sessions, such as arranging independent practice, teaching other members of the multidisciplinary team or family member how to help the patients, which may have increase the patients' activity levels. Nor did we formally record the treatment provided when the aim of treatment was not on balance and mobility, as this was not the aim of the study.

\section{Clinical Messages}

- In the participating stroke units (in North-West England), stroke physiotherapy for balance and mobility problems features low dose therapist-led practice, mainly of walking and sit-to-stand.

- Mobilisation techniques and other interventions to normalise tone and movement patterns are rarely used.

- Use of staffing resources appear inefficient. Most treatment sessions involve two qualified therapists: 1 patient. 
Physiotherapy for balance and mobility after stroke

\section{References}

1. Bohannon RW, Williams AA, Smith MB. Rehabilitation goals of patients with hemiplegia, Int J Rehabil Res, 1988. 11:181-183.

2. Plant S \& Tyson SF. How is goal-setting practised during in-patient stroke rehabilitation? Clin Rehabil e-pub July-17-2017 DoI 10.1177/0269215517719485

3. Van Peppen RP, Kwakkel G, Wood-Dauphinee S, et al. The impact of physical therapy on functional outcomes after stroke: what's the evidence? Clin Rehabil. 2004;18:833862.

4. French B, Thomas LH, Leathley MJ et al. Repetitive task training for improving functional ability after stroke. Cochrane Database of Systematic Reviews 2007, Issue 4. Art. No.: CD006073. DOI: 10.1002/14651858.CD006073.pub2.

5. Lohse KR, Lang CE, Boyd LA. Is More Better? Using Metadata to Explore DoseResponse Relationships in Stroke Rehabilitation. Stroke 2014;45:2053-2058

6. Foley N, Pereira S, Salter K et al. Are Recommendations Regarding Inpatient Therapy Intensity Following Acute Stroke Really Evidence-Based? Topics in Stroke Rehabil 2012; 19; 2: 96-103

7. National Stroke Foundation. Clinical guidelines for Stroke Management 2017. https://informme.org.au/guidelines (last accessed 18th December, 2017).

8. Hebert D, Teasell R on behalf of the Stroke Rehabilitation Writing Group of Canadian Stroke Best Practices and Advisory Committee. Canadian Stroke Best Practice Recommendations, 2015; http://www.strokebestpractices.ca/stroke-rehabilitation/ (last accessed $18^{\text {th }}$ December 2017)

9. Sentinel Stroke National Audit Programme. 2017 Quarterly Summary Report April - July 2017. https://www.strokeaudit.org/results/Clinical-audit/National-Results.aspx. Last accessed 18th December 2017. 
Physiotherapy for balance and mobility after stroke

10. Tyson SF \& Selley A. The Content of Physiotherapy for Postural Control in People after Stroke: An Observational Study. Disab \& Rehabil 2006:28:13-14;865-872

11. Tyson SF, Connell LA, Busse M et al. What treatment packages do UK physiotherapists use to treat postural control and mobility problems after stroke? Disab \& Rehabil $2009 ; 31: 18 ; 1494-15$

12. Veerbeek JM, Koolstra M, Ket JCF et al. Effects of Augmented Exercise Therapy on Outcome of Gait and Gait-Related Activities in the First 6 Months after Stroke: A MetaAnalysis. Stroke. 2011;42:3311-3315

13. DeWit L, Putman K, Schuback B et al. Motor and functional recovery after stroke: a comparison of 4 European rehabilitation centers. Stroke 2007:38;2101-07

14. Putman K, DeWit L, Schupp W et al. Use of time by physiotherapists and occupational therapists in a stroke rehabilitation unit: A comparison between four European rehabilitation centres. Disab \& Rehabil 2006:28:22: 1417-1424

15. Bayley M, Hurdoward A, Richards CL et al. Barriers to implementation of stroke rehabilitation evidence: findings from a multi-site pilot project. Disab \& Rehabil 2012; $34: 19: 1633-1638$

16. Mudge S, Hart S, Murugan S et al. What influences the implementation of the New Zealand stroke guidelines for physiotherapists and occupational therapists? Disab \& Rehabil 2017:39:5:511-51

17. Kristensen HK, Ytterberg C, Jones DL et al. Research-based evidence in stroke rehabilitation: an investigation of its implementation by physiotherapists and occupational therapists. Disab \& Rehabil 2016:38:26:2564-2574

18. Trebble TM, Hansi N, Hydes T et al. Process mapping the patient journey through health care: an introduction. $B M J, 2010: 341: c 4078$ 
Physiotherapy for balance and mobility after stroke

19. Clarke DJ, Burton LJ, Tyson SF et al. Why do inpatient stroke survivors not receive the recommended amount of active therapy? A mixed-methods case-study evaluation in eight stroke units Clin Rehabil e-published March 27, 2018.

https://doi.org/10.1177/0269215518765329

20. Collen FM, Wade DT, Robb GF et al. The Rivermead Mobility Index: A further development of the Rivermead Motor Assessment. Int Disab Stud 1990;13;2;6-9.

21. Lang CE, MacDonald JR, Gnip C. Counting Repetitions: An Observational Study of Outpatient Therapy for People with Hemiparesis Post-Stroke. J Neurologic Phys Ther 2007;31: $3-1$

22. English C, Hillier S, Kaur G et al. People with stroke spend more time in active task practice, but similar time in walking practice, when physiotherapy is provided in circuit classes compared to individual therapy sessions: an observational study. J Physiother 2014;60: $50-54$

23. Royal College of Physicians of London, Intercollegiate Stroke Working Party. National Clinical Guideline for Stroke. 5th edition. London; 2016. https://www.rcplondon.ac.uk/guidelines-policy/stroke-guidelines (last accessed 18th December, 2017).

24. Mehrholz J, Thomas S, Elsner B. Treadmill training and body weight support for walking after stroke. Cochrane Database of Systematic Reviews 2017, Issue 8. Art. No.:

CD002840. DOI: 10.1002/14651858.CD002840.pub4.

25. Mehrholz J, Thomas S, Pohl M et al. Electromechanical-assisted training for walking after stroke. Cochrane Database of Systematic Reviews 2017, Issue 5.

26. English $\mathrm{C}$ and Hillier S. Circuit class therapy for improving mobility after stroke: A systematic review. J Rehabil Med 2011; 43: 565-57 
Physiotherapy for balance and mobility after stroke

Table 1. The amount of time spent upright and the number of steps taken during treatment.

\begin{tabular}{|l|l|l|}
\hline & $\begin{array}{l}\text { Mean (sd, range) of total time } \\
\text { spent upright per session } \\
\text { (includes standing and walking) } \\
\text { (minutes) }\end{array}$ & $\begin{array}{l}\text { Mean (sd, range) } \\
\text { number of steps } \\
\text { taken per session } \\
\text { (steps) }\end{array}$ \\
\hline All treatment sessions & $11.24(7 ; 0.4-44$ & $202(118 ; 4-1,108$ \\
\hline Treatment sessions involving a & $29(14.3 ; 9-43)$ & $636(434 ; 92-1,108)$ \\
\hline treadmill & & $182(201 ; 4-913$ \\
\hline involving a treadmill & $29(14.2 ; 4-57)$ & \\
\hline
\end{tabular}


Figure 1. Frequency of treatment objectives reported by the lead physiotherapist at the end of each treatment session. (NB $d a r k b a r s$ involve the practice of functional activites, light bars involve internvetions focussing on impairments)

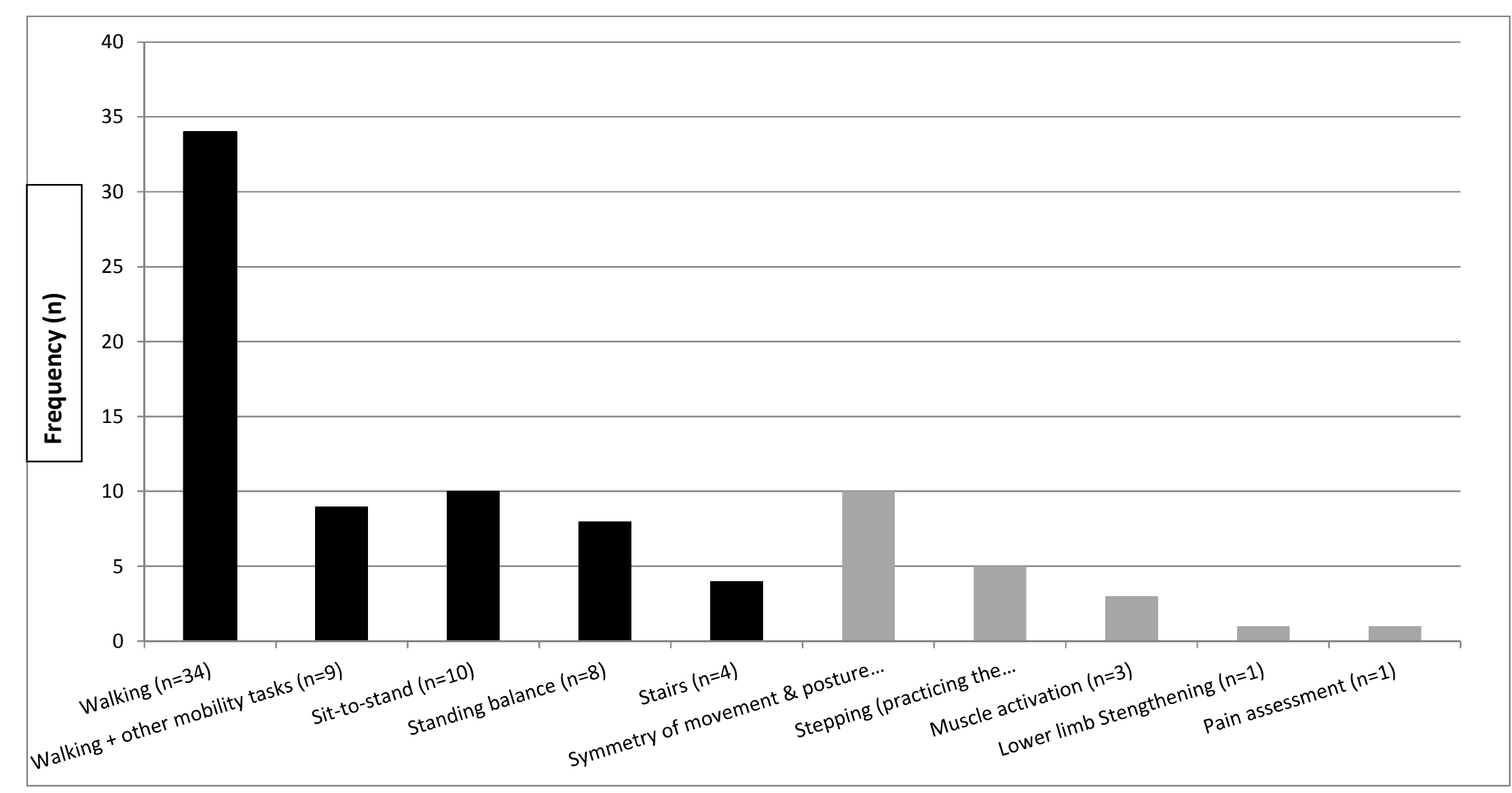




\section{Physiotherapy for balance and mobility after stroke}

Figure 2. The percentage of treatment sessions in which each intervention was used

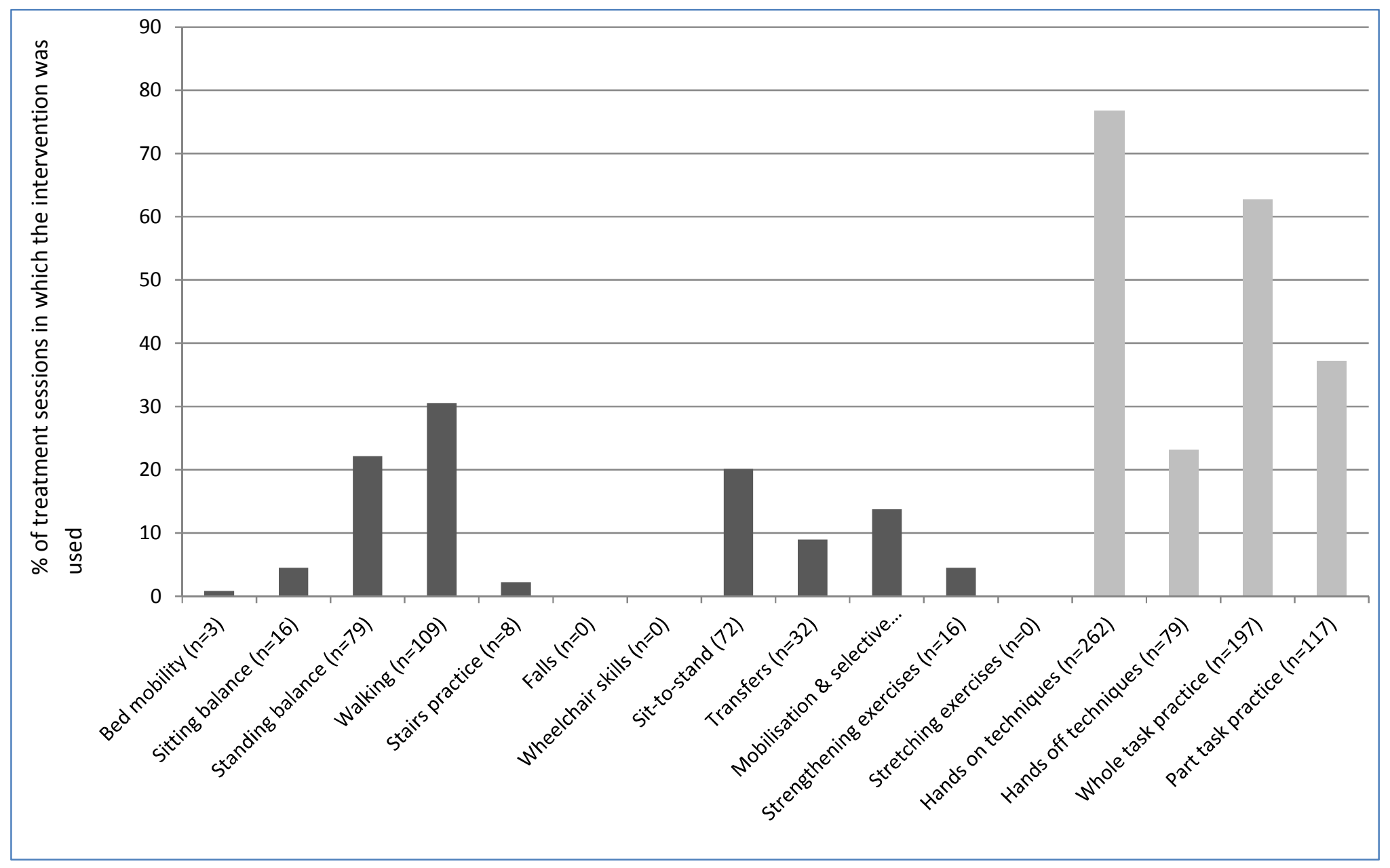

